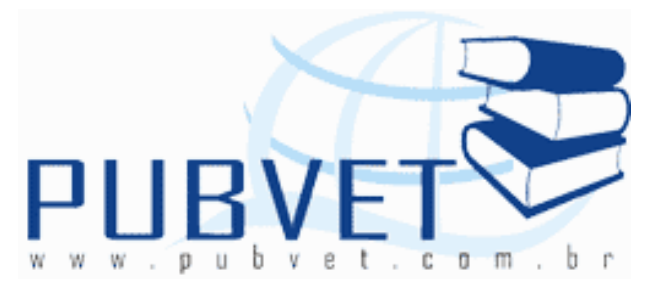

PUBVET, Publicações em Medicina Veterinária e Zootecnia.

\title{
Endometrite persistente pós-cobertura
}

Filipe Martin da Silva ${ }^{1}$, Hélio Blume ${ }^{1}$, Rodrigo Arruda de Oliveira ${ }^{2}$

${ }^{1}$ UPIS Faculdades Integradas, Departamento de Medicina Veterinária, Fazenda Lagoa Bonita, Campus Rural, CEP 73350-980, Brasília/DF, Brasil. E-mail: ms.filipe_vet@hotmail.com

2 Universidade de Brasília, Faculdade de Agronomia e Medicina Veterinária, Departamento de Reprodução Animal, Campus Universitário Darcy Ribeiro, Instituto Central de Ciências, Ala Sul, Asa Norte, CEP 70910-900, Brasília/DF, Brasil.

\section{Resumo}

Atualmente, a endometrite é a maior causa de infertilidade nas éguas, sendo apontada como a terceira afeç̧ão clinica mais comum depois da síndrome cólica e das afeç̧ões do trato respiratório. O processo inflamatório induzido pós-cobertura pelo sêmen e por microrganismos é um evento fisiológico e necessário para manter o ambiente uterino adequado para o recebimento do embrião. Entretanto, algumas éguas consideradas susceptíveis à endometrite são incapazes de debelar esse processo inflamatório no tempo adequado e desenvolvem endometrite persistente pós-cobertura, resultando em altos índices de perda embrionária. Para isso o útero possui um mecanismo eficiente de defesa, que por inúmeros fatores pode se tornar falho, o que leva a um 
SILVA, F.M., BLUME, H. e OLIVEIRA, R.A. Endometrite persistente pós-cobertura. PUBVET, Londrina, V. 8, N. 20, Ed. 269, Art. 1796, Outubro, 2014.

processo patológico e a um grande prejuízo econômico nos criatórios. Palavras-chave: égua, infertilidade, reação endometrial

\title{
Persistent endometritis pos-breeding
}

\begin{abstract}
Nowadays, endometritis is the major cause of infertility in mares, being considered the third most common clinical condition after colic syndrome and disorders of the respiratory tract. The inflammatory process induced postbreeding by semen and by microorganisms is a physiological and necessary to maintain the adequate uterine environment for the embryos reception. However, some mares considered susceptible to endometritis are unable to overcome this inflammatory process in adequate time and develop post breeding persistent endometritis, resulting in high embryonic loss rates. For that, the uterus has an efficient defense mechanism, which can be flawed for many factors, which leads to a pathological process and a large economic loss in stud farms.
\end{abstract}

Keywords: endometrial reaction, infertility

\section{Introdução}

O estudo da endometrite na espécie equina desperta o interesse há vários anos em todo mundo. Isso se deve ao fato de ser uma das maiores causas de subfertilidade e infertilidade em éguas.

É sabido que o processo inflamatório induzido pós-cobertura pelo sêmen e por microrganismos é um evento fisiológico e necessário para manter o ambiente uterino adequado para o recebimento do embrião. Entretanto, algumas éguas consideradas susceptíveis à endometrite são incapazes de debelar esse processo inflamatório no tempo adequado e desenvolvem endometrite persistente pós-cobertura, resultando em altos índices de perda embrionária. 
SILVA, F.M., BLUME, H. e OLIVEIRA, R.A. Endometrite persistente pós-cobertura. PUBVET, Londrina, V. 8, N. 20, Ed. 269, Art. 1796, Outubro, 2014.

Os primeiros estudos para identificar as possíveis causas da susceptibilidade dessas éguas se baseavam na hipótese da deficiência de algum fator imunológico envolvido no processo de limpeza uterina. Entretanto, muitos autores propuseram que a deficiência poderia estar no mecanismo físico do processo de limpeza que inclui tanto as contrações uterinas quanto a drenagem linfática. As descobertas dessas pesquisas foram muito importantes para um delineamento mais correto dos tratamentos a serem utilizados.

Objetivou-se com essa revisão apresentar a etiopatogenia, diagnóstico e principais formas de tratamento da endometrite persistente pós cobertura.

\section{Etiopatogenia da reação endometrial pós cobertura}

Atualmente, a endometrite é a maior causa de infertilidade nas éguas BRINSKO et al., (2011), sendo apontada como a terceira afecção clinica mais comum depois da cólica e das afecções do trato respiratório (TROEDSON, 1999).

Comumente o útero da égua é exposto a uma grande variedade de microorganismos durante o processo de cobertura, devido à existência de uma pressão uterina negativa, responsável pela deposição do sêmen dentro do útero da égua. Com isso, muitas bactérias da flora normal da cavidade vaginal são deslocadas para o interior do útero no momento da cópula (HINRICHS et al., 1988). Essa deposição do sêmen no útero induz uma inflamação fisiológica, que passa a ser considerada como uma endometrite transitória. Esta inflamação possui um papel importante para a remoção dos espermatozoides excedentes, plasma seminal, debris e contaminantes que acabam adentrando o útero (HEMBERG et al., 2005).

Éguas que conseguem eliminar os patógenos por meio de seus mecanismos de defesa uterina após a cobertura, possuem uma boa fertilidade. Aquelas que possuem falha neste mecanismo de limpeza podem desenvolver uma endometrite pós-cobertura ou uma endometrite aguda, e se esta não for tratada poderá se tornar crônica (LeBLANC, 2010). 
SILVA, F.M., BLUME, H. e OLIVEIRA, R.A. Endometrite persistente pós-cobertura. PUBVET, Londrina, V. 8, N. 20, Ed. 269, Art. 1796, Outubro, 2014.

\section{Mecanismos de defesa uterina}

O ambiente uterino ideal proporciona condições para que ocorra inicialmente o transporte espermático até $o$ sítio de fecundação e posteriormente um perfeito desenvolvimento embrionário. O fluido uterino é composto basicamente por substratos energéticos, enzimas, íons, vitaminas, prostaglandinas, aminoácidos, peptídeos, hormônios e proteínas séricas, e é formado pelo extravasamento de componentes do sangue pelo endométrio e por substâncias intrauterinas, onde o sangue e o fluido uterino se comunicam através dos vasos sanguíneos, o que permite a troca de substâncias entre eles (McRAE, 1988).

Logo para que haja um ambiente uterino ideal é necessário que os mecanismos de defesa físicos, humorais e celulares estejam funcionando corretamente e em perfeita harmonia.

\section{Mecanismo de defesa física}

Associado as defesas humorais e celulares, o útero conta com a proteção das barreiras físicas, por exemplo, vulva e vagina, prega vestíbulo-vaginal e a cérvix (LeBLANC et al., 1995).

A contratilidade do miométrio tem um papel muito importante na limpeza uterina pós-cobertura e na eliminação de subprodutos inflamatórios (LeBLANC et al., 1994). De acordo com TROEDSSON (1999), a contração uterina é responsável pela expulsão de debris celulares resultantes da lesão tecidual e da morte celular. Para que este mecanismo funcione, é preciso ter um bom relaxamento e abertura da cérvix.

A atividade contrátil uterina ocorre da despolarização e da repolarização da membrana plasmática das células dos músculos lisos do útero. Em éguas sadias, as contrações são mais prolongadas, com maior intensidade e em maior número; as quais seguem um sentido a partir da ponta do corno uterino em direção a cérvix. E em éguas susceptíveis não existe um padrão rítmico, o útero se contrai em direção da ponta do corno uterino, ou seja, no sentido contrário da eliminação do conteúdo pelo órgão (REITZENSTEIN et al., 2002). 
SILVA, F.M., BLUME, H. e OLIVEIRA, R.A. Endometrite persistente pós-cobertura. PUBVET, Londrina, V. 8, N. 20, Ed. 269, Art. 1796, Outubro, 2014.

Portanto, neste grupo de éguas, há ausência de harmonia da atividade mioelétrica e esta ausência consiste na causa primária da endometrite persistente pós-cobertura (TROEDSSON, 1999).

A deficiência de um padrão rítmico em éguas susceptíveis está relacionado a alguns fatores, tais como uma hipertrofia da musculatura lisa do útero, por seguidas gestações ou por um fator intrínseco da própria égua, podendo ser um defeito neuronal na sinalização contribuindo para um mau funcionamento contrátil do miométrio (REITZENSTEIN et al., 2002). Outro fator que pode estar associado é a diminuição da frequência, intensidade e duração da atividade miometrial, em decorrência de mudanças na liberação local ou sistêmica de prostaglandina e ocitocina (RIGBY et al., 2001). Em éguas pluríparas, há alterações degenerativas que ocorrem no útero de éguas devido à idade e número de partos, como interações neuromusculares alteradas, ou falha na drenagem linfática. A dilatação parcial do útero ou deslocamento caudo-ventral é um dos responsáveis por tal patologia (LeBLANC, 2003).

Além das contrações miometriais, a drenagem linfática pode ser importante no processo de "clearance" uterino. Os vasos linfáticos e os linfonodos drenam da submucosa e do lúmen uterino o excesso de fluido (LeBLANC et al., 1995). Estes autores realizaram um estudo para comprovar a hipótese de que existe diferença qualitativa na eficácia e na taxa de drenagem linfática uterina entre éguas normais e susceptíveis à endometrite pela administração de nanquim no miométrio e no lúmen uterino dessas éguas. Nesse estudo foi avaliada a capacidade das éguas absorverem o nanquim através dos vasos linfáticos. Os resultados obtidos confirmaram a hipótese de que a eficiência e a taxa de drenagem linfática estavam diminuídas nas éguas susceptíveis quando comparadas às resistentes e o nanquim permaneceu por um tempo prolongado induzindo a uma severa reação inflamatória aguda no endométrio.

A disfunção do mecanismo de drenagem linfática pode ser responsável pelo atraso na remoção do nanquim e subsequente severo processo 
SILVA, F.M., BLUME, H. e OLIVEIRA, R.A. Endometrite persistente pós-cobertura. PUBVET, Londrina, V. 8, N. 20, Ed. 269, Art. 1796, Outubro, 2014.

inflamatório. Além disso, a pouca dilatação cervical também pode ser responsável pelo atraso no "clearance" uterino. Ainda observaram que as éguas susceptíveis tinham útero largo e penduloso exibindo lacunas linfáticas, "aninhamento" glandular com fibrose e inflamação nos exemplares de biópsia. Essas alterações anatômicas e patológicas do útero podem ter impedido o fluxo linfático nessas éguas. Os autores sugeriram que a disfunção linfática pode contribuir para a infertilidade (LeBLANC et al., 1995).

Outro problema associado no grupo de éguas susceptíveis é o acúmulo de óxido nítrico no lúmen uterino (ALGHAMDI et al.,2005). O óxido nítrico é formado a partir da lise de bactérias dentro dos neutrófilos, das células epiteliais e endoteliais e dos macrófagos (MACKAY, 2000). Esta substância é responsável pelo relaxamento da musculatura lisa do útero, e tem um papel importante como mensageiro inter e intracelular, pois controla o tônus vascular, a neurotransmissão, diferenciação celular, produção de hormônios, ativação das células do sistema imune, expressão gênica e na fisiologia ovariana.

Nas éguas susceptíveis, o óxido nítrico promove uma redução na atividade miolétrica (que fica abaixo da linha basal entre 7 a 19 horas do início do processo inflamatório), pelo fato de ele causar o relaxamento da musculatura lisa do útero (ALGHAMDI et al., 2005).

Segundo NIKOLAKOPOULOS \& WATSON (1999) e TROEDSSON (1999) éguas com defeito na contratilidade miometrial aumentam a susceptibilidade a desenvolverem à endometrite persistente pós-cobertura. Éguas alocadas no grupo das susceptíveis apresentam um retardo de duas horas na eliminação de patógenos e de espermatozoides em relação às éguas sadias.

Mecanismo de defesa humoral

O útero possui uma característica de tecido linfóide associado à mucosa, devido a sua capacidade de produzir e secretar imunoglobulinas. O contato do sêmen e seus constituintes com o útero e cérvix induz uma série de reações e mecanismos celulares e humorais. 
SILVA, F.M., BLUME, H. e OLIVEIRA, R.A. Endometrite persistente pós-cobertura. PUBVET, Londrina, V. 8, N. 20, Ed. 269, Art. 1796, Outubro, 2014.

Em uma lavagem uterina, foram isolados seis classes de imunoglobulina IgGa, IgGb, IgGc, IgT,IgA e IgM (KATILA, 1996; TROEDSSON, 1999). A predominância no muco cérvico-vaginal foi de IgA. Esta imunoglobulina correspondeu entre 1 e $8 \%$ da totalidade de imunoglobulinas circulantes. Possui grande presença uterina, chegando de 40 a 58\%, a imunoglobulina IgM está em grande quantidade no lúmen uterino (TROEDDSON, 1999).

As imunoglobulinas IgM e IgA são produzidas localmente pelo trato genital. A transdução passiva de imunoglobulinas para o lúmen uterino é mínima. Alguns estudos imunohistoquímicos do endométrio demonstram que as concentrações das imunoglobulinas livres e a quantidade de células que as contêm, ficam em nível estável durante o ciclo estral (TROEDDSON, 1999).

Sabe-se que o mecanismo de defesa realizada por anticorpos é muito importante no combate a infecções bacterianas e sua posterior eliminação. Entretanto, a sua deficiência não é indicativo para a susceptibilidade de algumas éguas a este tipo de infecção (KATILA, 1996). As éguas susceptíveis podem apresentar valores de anticorpos iguais ou superiores às éguas resistentes à endometrite. Esse fato sugere que a defesa imunológica se encontra funcional nas éguas susceptíveis e que o progresso da endometrite se deve a outros fatores envolvidos na limpeza uterina: como dilatação cervical, contratilidade do miométrio e drenagem linfática (KATILA, 1996; TROEDSSON, 1999). DeLL'AQUA Jr. et al., (2006) cita que o grupo de éguas susceptíveis não apresentam grande variação em relação à concentração de IgA em um processo de endometrite, e que, após a inseminação artificial, o fator mais importante na defesa uterina é a defesa celular juntamente com os mecanismos físicos de defesa uterina.

\section{Mecanismo de defesa celular}

O contato dos componentes do ejaculado com as células uterinas e cervicais desencadeiam também uma resposta inflamatória uterina póscobertura. O evento principal corresponde à síntese e liberação de mediadores quimiotáxicos, que resulta no influxo de polimorfonucleares neutrófilos para o 
SILVA, F.M., BLUME, H. e OLIVEIRA, R.A. Endometrite persistente pós-cobertura. PUBVET, Londrina, V. 8, N. 20, Ed. 269, Art. 1796, Outubro, 2014.

lúmen uterino em resposta ao antígeno (SCHUBERTH et al., 2008). Os neutrófilos são as primeiras células inflamatórias a chegarem ao local inflamado. KATILA (1996) observou estas células no lúmen uterino no período de 30 minutos após a inseminação. Estas células, que constituem a primeira linha de defesa do organismo, atuam na eliminação de antígenos por meio de fagocitose (GALINDO et al., 2003). Assim, após o contato do sêmen com o útero, ocorre uma forte reação inflamatória entre 4 e 24 horas (CARD, 2005). O pico da reação ocorre entre 6 e 12 horas, e decresce entre 24 e 48 horas (TROEDSSON, 1999). Servem de agentes quimiotáxicos para os polimorfonucleares no útero, não só os produtos do complemento como o leucotrieno B4, a prostaglandina E, a prostaglandina F2 alfa (TROEDSSON, 1999; TROEDSSON et al., 2001) mas também citocinas, quimiocinas e outros mediadores que, juntos, montam uma resposta celular (SCHUBERTH et al., 2008).

Os principais fatores pró-inflamatórios estimulam também a infiltração dos tecidos uterinos e cervicais pelos macrófagos, células dendítricas e granulócitos (SCHUBERTH et al., 2008). Uma vez iniciado o processo inflamatório, uma série de mediadores pró-inflamatórios é liberada pelos neutrófilos em fagocitose, pelas células do endotélio vascular, por células endometriais lesadas e pelos macrófagos ativados pela inflamação. As principais funções desses mediadores são atrair mais células de defesa para o local da inflamação, facilitando o acesso dessas células e melhorando a eficiência da eliminação do agente agressor. Segundo KATILA (1996), não existe nenhuma diferença na migração dos polimorfonucleares entre éguas resistentes e susceptíveis.

Embora as éguas susceptíveis tenham concentrações mais elevadas de anticorpos nas suas secreções uterinas quando comparadas as éguas resistentes, elas têm uma capacidade de limpeza mecânica diminuída e, como tal, acumulam-se enzimas inflamatórias no útero que podem destruir mediadores inflamatórios benéficos. Isso resulta em uma opsonização insuficiente de antígenos que, escapam à fagocitose pelos polimorfonucleares 
SILVA, F.M., BLUME, H. e OLIVEIRA, R.A. Endometrite persistente pós-cobertura. PUBVET, Londrina, V. 8, N. 20, Ed. 269, Art. 1796, Outubro, 2014.

(TROEDSSON, 1999). Esta acumulação de enzimas leva a uma degradação enzimática dos tecidos que pode ser responsável por alterações fibróticas degenerativas no endométrio (TROEDSSON, 1999).

Os neutrófilos são células fagocitárias; Portanto, importantes para a limpeza do ambiente uterino, não só da contaminação acidental por microrganismos após inseminação como da eliminação dos espermatozoides remanescentes, na presença de opsoninas (SCHUBERTH et al., 2008; TROEDSSON, 1999). Considera-se, no entanto, que os espermatozoides velhos, mortos ou não capacitados são o alvo preferencial e que os neutrófilos têm um papel ativo na seleção dos espermatozoides removendo aqueles que estão mortos ou imóveis e os que se encontram danificados (SCHUBERTH et al., 2008).

A cascata do complemento desencadeia várias reações, com o intuito de defender o organismo contra um agente agressor. Estas reações incluem o aumento de permeabilidade vascular, a quimiotaxia, a opsonização antes da fagocitose, a ativação das lipases membranárias e a lise dos organismos-alvo (TROEDSSON, 1999, 2001). O espermatozoide equino por si só é capaz de ativar a cascata complemento presente na secreção uterina, ocorrendo à clivagem do fator C5 em C5a e C5b. Este fenômeno resulta na quimiotaxia mediada pelo fator de complemento $\mathrm{C} 5 \mathrm{a}$ e consequentemente em uma migração de polimorfonucleares para o lúmen uterino (TROEDSSON et al., 2001; TROEDSSON, 2006). Já o fator de complemento C3b opsoniza bactérias e espermatozoides, pois facilita a fagocitose e remoção desses produtos do trato reprodutivo (TROEDSSON et al., 2001).

As respostas imunitárias agudas do útero das éguas são também moduladas por citocinas como o fator de estimulação das células de defesa granulócito-macrófago, interleucina1beta, interleucina 6, fator de necrose tumoral alfa (SCHUBERT et al, 2008). A interleucina 6 é produzida por mastócitos e macrófagos em resposta à presença de endotoxinas bacterianas e tem um efeito protetor no endométrio de éguas jovens durante o estro após um evento pró-inflamatório. Esta citocina promove a diferenciação das células 
SILVA, F.M., BLUME, H. e OLIVEIRA, R.A. Endometrite persistente pós-cobertura. PUBVET, Londrina, V. 8, N. 20, Ed. 269, Art. 1796, Outubro, 2014.

B, das células $T$ e estimula a produção de proteínas de fase aguda (LEWIS, 2004, PRESCOTT et al., 2005). É responsável também pela regulação da transição de uma fase de dominância dos neutrófilos para uma fase dominada pelos macrófagos (LIEPINA et al, 2010), onde esta células são responsáveis pela segunda linha de combate aos antígenos uterinos.

A interleucina 12 é responsável pela indução da produção de interferon- $\gamma$ e estimula a citotoxicidade das células Natural Killer (LEWIS, 2004). Por sua vez, a interleucina 8, uma potente quimiocina, induz uma quimiotaxia dos polimorfonucleares porque promove tanto migração para o lúmen uterino, como a degranulação das células fagocitárias com consequente liberação de várias enzimas que ajudam a completar a digestão celular e porque estimula a libertação de intermediários reativos do oxigênio, como o superóxido, o peróxido de hidrogênio e o radical hidroxila (LEWIS, 2004; PRESCOTT et al., 2005; LIEPINA et al, 2010).

Estes subprodutos são extremamente tóxicos e eficazes na invasão e morte dos microrganismos e são produzidos por enzimas lisossomais dependentes de oxigênio portanto um aumento do consumo do oxigênio para produção de ATP é necessário para a fagocitose (PRESCOTT et al., 2005).Outro potente mediador da resposta inflamatória e citotóxica é o fator de necrose tumoral alfa. É responsável por uma grande variedade de efeitos devido à sua capacidade de mediar a expressão de genes de fatores de crescimento e de citocinas e a expressão de fatores, receptores, mediadores inflamatórios e proteínas de fase aguda.

Também possui um papel importante no desenvolvimento de resistências a infecções servindo como estimulador imunitário e mediador da resposta inflamatória (PRESCOTT et al., 2005). O fator de necrose tumoral alfa estimula também a produção endometrial de prostaglandina F2 alfa (LEWIS, 2004). A expressão aumentada do RNA mensageiro do fator de necrose tumoral alfa tem sido recentemente revelada como sendo um elemento muito importante na patogénese da endometrite pós-cobertura (LIEPINA et al, 2010). 
SILVA, F.M., BLUME, H. e OLIVEIRA, R.A. Endometrite persistente pós-cobertura. PUBVET, Londrina, V. 8, N. 20, Ed. 269, Art. 1796, Outubro, 2014.

Os lisossomas dos neutrófilos contém uma série de enzimas lisossomais, incluindo as peroxidases e enzimas hidrolíticas (lisozima, fosfolipase $A$, a ribonuclease, a desoxirribonuclease, proteases) e as enzimas dependentes do oxigênio (PRESCOTT et al., 2005), cuja atividade foi demonstrada no endométrio da égua (TIZARD, 1998). Estes organelas possuem também proteinases neutras, colagenases, elastases e as gelatinases que favorecem o aporte celular e iniciam imediatamente o processo de reparação do endométrio (MACKAY, 2000). A plasmina é uma enzima fibrinolítica que ao exercer sua função liberta fragmentos peptídicos que são quimiotáticos para os neutrófilos (TIZARD, 1998). Como são potentes opsoninas para os neutrófilos, são encontradas em altas concentrações em locais de inflamação aguda (TIZARD, 1998).

Recentemente foi também demonstrado que os neutrófilos produziam intermediários reativos do nitrogênio. Estas moléculas incluem o óxido nítrico e as suas formas oxidadas, nitrato e nitrito. O óxido nítrico é provavelmente o mais eficaz sendo responsável pela lise de bactérias no interior do neutrófilo (MACKAY, 2000; PRESCOTT et al., 2005). Os eicosanóides, como a prostaglandina F2 alfa e o leucotrieno B4 também, são conhecidos pelos seus efeitos benéficos para a saúde uterina. Já a prostaglandina F2 Alfa é responsável por um efeito inibidor da função imunitária uterina, particularmente da função dos polimorfonuclears. A prostaglandina F2 alfa, além de induzir alterações na permeabilidade vascular e estimular a contratilidade uterina, induz a luteólise. Este fenômeno resulta numa redução da concentração de progesterona circulante, reduzindo o seu efeito imunossupressor sobre as defesas imunitárias uterinas (LEWIS, 2004).

O aumento da prostaglandina F2 Alfa uterina é provavelmente também responsável pelo aumento da atividade da fosfolipase A2 uterina e da ciclooxigenase2 (COX-2), que por sua vez produzem ácido araquidônico livre e o convertem em prostaglandina F2 Alfa ou em outros produtos (leucotrienoB4) (LEWIS, 2004). Como a inflamação aguda pode causar danos aos tecidos, deve ser mantida tanto quanto possível sob controle. 
SILVA, F.M., BLUME, H. e OLIVEIRA, R.A. Endometrite persistente pós-cobertura. PUBVET, Londrina, V. 8, N. 20, Ed. 269, Art. 1796, Outubro, 2014.

O mesmo estímulo que induz a liberação dos mediadores próinflamatórios promove o aparecimento de mecanismos e de moléculas que atuam terminando o processo inflamatório, assim que ele deixe de ser necessário. Essas moléculas atuam inibindo a produção das citocinas próinflamatórias, bloqueando os receptores celulares ou induzindo a morte celular.

A interleucina 10 apresenta um potente efeito antiinflamatório através da inibição da produção das citocinas pró-inflamatórias do endométrio (FUMUSO et al., 2006). As células produzem um subtipo de Interleucina 1 que não age como citocina, mas que bloqueia os receptores para a Interleucina 1 impedindo os seus efeitos. A interleucina 6 , que logo após a agressão é uma citocina próinflamatória, pode num estágio mais avançado induzir a apoptose dos neutrófilos, eliminando os subprodutos inflamatórios sem o risco de que sejam libertados no próprio tecido (MACKAY 2000). A progesterona suprime a produção da interleucina 6,8 e 12 (LEWIS, 2004).

\section{Alterações histológicas}

O grupo de éguas susceptíveis possui alguns fatores em comum como: uma conformação perineal alterada, idade avançada, localização uterina fora dos padrões anatômicos ou falha no clearance uterina devido há uma deficiente contração miometrial (CARD, 2005), além de outras, como lacunas linfáticas, angiopatias e fibrose periglandular (ZENT, 1998).

As angiopatias em éguas reprodutoras estão associadas com o número de partos e o avançar da idade (LeBLANC, 2003). Em éguas idosas e com elevado número de partos observa-se aumento de alterações inflamatórias degenerativas no sistema vascular uterino como mudanças angioescleróticas, caracterizadas por moderada esclerose vascular. Ainda, em éguas velhas com elevado número de partos, registra-se a chamada esclerose da prenhez que é o aumento de angiose caracterizado como aumento de ruptura da membrana elástica interna, atrofia medial, elastose adventicial e calcificação medial da parede dos vasos (LeBLANC et al., 2010). As alterações hemodinâmicas e hormonais durante a prenhez e o puerpério induzem a remodelagem vascular. 
SILVA, F.M., BLUME, H. e OLIVEIRA, R.A. Endometrite persistente pós-cobertura. PUBVET, Londrina, V. 8, N. 20, Ed. 269, Art. 1796, Outubro, 2014.

O ciclo vascular de crescimento durante a prenhez e a involução no pós-parto resulta em progressiva degeneração vascular. Em adição, severa angiose é associada à flebectasia e linfangiectasia que podem estar relacionadas à infertilidade em éguas velhas e, além disso, à redução da circulação uterina sanguínea e linfática

A degeneração vascular endometrial também contribui para o atraso na limpeza uterina. Esclerose dos vasos (elastose, fibrose, fibroelastose, fibrose perivascular e processos de calcificação) tem sido registrada no exame histopatológico do endométrio de éguas com acúmulo anormal de fluído intrauterino. A angiose parece reduzir, indiretamente, a fertilidade por meio da menor perfusão endometrial e por distúrbio na drenagem uterina, causadas pela reduzida, função das veias e dos vasos linfáticos (linfangiectasia endometrial) que, consequentemente, levam à persistência do edema endometrial, formando as lacunas linfáticas (LeBLANC, 2003).

\section{Diagnóstico}

Para obter um diagnóstico definitivo da endometrite persistente póscobertura, deve-se levar em consideração o histórico da égua, pois éguas que já apresentaram problemas anteriores de endometrite, seja de caráter agudo ou crônica, terão mais chances de ter a endometrite persistente pós-cobertura (TROEDSSON, 1997). Todas as éguas destinadas à reprodução, seja por monta natural ou inseminação artificial, devem passar por um processo de inspeção para detectar defeitos de conformação vulvar e perineal e avaliação da cérvix.

Após esta avaliação será feito o exame de ultrassonografia transretal, que é de grande importância na detecção de fluído intrauterino antes da cobertura e até 24 horas após a cobertura (LEBLANC, 2010). BRINSKO et al., (2003) e BUCCA et al., (2008) relatam que a presença de dois ou mais centímetros de fluído uterino durante o cio ou de 6 a 36 horas pós cobertura é um bom indicativo que a égua esteja com a endometrite persistente póscobertura. 
SILVA, F.M., BLUME, H. e OLIVEIRA, R.A. Endometrite persistente pós-cobertura. PUBVET, Londrina, V. 8, N. 20, Ed. 269, Art. 1796, Outubro, 2014.

Para auxiliar no diagnóstico desta patologia, pode-se fazer uma citologia acompanhada de cultura bacteriana, contando o número de neutrófilos em 10 campos microscópicos (400x) e categorizar o grau de inflamação, como ausente (0-2 neutrófilos por campo), inflamação moderada (3-5 neutrófilos por campo) ou inflamação severa ( $>5$ neutrófilos por campo) (LeBLANC \& CAUSEY, 2009), e um crescimento significativo de patógenos.

O exame citológico na rotina de campo tem sido muito utilizado para diagnosticar a saúde reprodutiva da égua, além de ser um método prático e sem ter maiores dificuldades de execução. Porém, o exame citológico isolado não permite conhecer a etiologia do processo inflamatório.

\section{Terapias aplicadas à endometrite persistentes pós-cobertura}

O tratamento compreende vários procedimentos realizados antes e após a cobertura, onde se incluem a lavagem uterina, o uso de drogas ecbólicas, infusão de plasma homólogo enriquecido ou não com leucócitos e manejo das coberturas (TROEDSSON, 1997). Quando a égua apresentar problemas de conformação perineal ou vulvar deve-se fazer a correção cirúrgica do problema.

Em algumas manobras terapêuticas que visam minimizar o processo inflamatório, diminui-se o número de espermatozoides a ser inseminado, bem como o número de inseminações no ciclo.

\section{Lavagem Uterina}

A lavagem uterina pode ser realizada após 4 horas da introdução do sêmen no útero. Este período corresponde ao tempo que o espermatozoide leva para migrar até o oviduto, evitando assim qualquer interferência no transporte espermático e queda na fertilidade.

A lavagem do útero pode ser feita utilizando o Ringer Lactato aquecida com volume compatível e proporcional a capacidade uterina (LeBLANC, 2003). É recomendado que se faça ao menos 3 lavagens consecutivas ou até que o líquido uterino retirado esteja límpido. 
SILVA, F.M., BLUME, H. e OLIVEIRA, R.A. Endometrite persistente pós-cobertura. PUBVET, Londrina, V. 8, N. 20, Ed. 269, Art. 1796, Outubro, 2014.

Esta lavagem é indicada em animais que repetem o cio e animais que tenham mais de $2 \mathrm{~cm}$ de líquido intrauterino (visualizado pela utrassonografia) pré ou pós a cobertura (BRINSKO et al., 2003). É indicada esta remoção do fluido uterino porque estas secreções remanescentes no útero podem conter debris inflamatórios, que irão afetar negativamente a motilidade espermática e a fertilidade (VANDERWALL \& WOODS, 2003).

Para se certificar que todo fluido uterino foi eliminado, ao final da última lavagem uterina pode-se administrar ocitocina ou outra droga que estimule a contratilidade da musculatura do útero para ajudar na remoção dos resíduos remanescentes.

\section{Drogas ecbólicas}

Estas drogas estimulam a contratilidade miometrial otimizando a remoção de resíduos remanescentes no útero e ajudam a drenagem do útero de animais que tenham a dificuldade de fazer a "clearence" uterina.

A ocitocina é a droga ecbólica de eleição para a reprodução, sendo que ela induz contrações uterinas de grande amplitude por um período de mais ou menos 30 minutos durante o estro e no período de 48 horas após a ovulação (LEBLANC et al., 1994). A outra forma que a ocitocina atua é se ligando diretamente a receptores miometriais e com isso promove a liberação de prostaglandina F2 alfa. Múltiplas doses de ocitocina, no dia da ovulação e no dia seguinte, não têm efeito no processo de formação do corpo lúteo e, portanto, na produção de progesterona ou na taxa de prenhez.

Os receptores de ocitocina no miométrio e no oviduto das éguas, estão presentes em maior número durante o fim do diestro e no estro (RIGBY et al., 1999) e, portanto, o seu efeito diminui após a ovulação, pois seu número de receptores varia conforme a fase do ciclo estral, (maior na fase estrogênica e menor na fase pós ovulatória).

A maioria das éguas responde rapidamente, eliminando o fluido quase imediatamente. As doses recomendadas variam entre 10 e 25 UI, administradas via intramuscular ou intravenosa (KNUTTI et al., 2000). No 
SILVA, F.M., BLUME, H. e OLIVEIRA, R.A. Endometrite persistente pós-cobertura. PUBVET, Londrina, V. 8, N. 20, Ed. 269, Art. 1796, Outubro, 2014.

período pós ovulatório, uma maior dose de 25 UI deve ser administrada (VERONESI et al., 2006).

A completa limpeza uterina ocorre em 24 horas após o tratamento com ocitocina, confirmando a eficácia dos hormônios ecbólicos exógenos em útero que contenham fluídos remanescentes. (CADARIO et al., 1999).

Em algumas éguas a ocitocina pode não ter um efeito satisfatório, devido alguns fatores tais como: baixo número de receptores, útero penduloso, cérvix fechada ou fibrosada, (VON REITZENSTEIN et al.,2002). Neste caso, não se deve exceder a dose recomenda citada anteriormente, pois a ocitocina quando aplicada em altas doses pode causar contrações tetânicas, acarretando em acúmulo de liquido intrauterino, segundo CADARIO et al.,(1999). Quando houver este tipo de situação é indicado uso de outras drogas ecbólicas, por exemplo. O cloprostenol, que, de acordo com COMBS et al., (1996) produziu reposta uterina mais consistente que a ocitocina, onde a contração produzida por esta droga é mais prolongada após a sua aplicação.

\section{Anti-inflamatórios esteróides}

O uso de anti-inflamatório não esteroidal para combater a reação inflamatória após a inseminação artificial se mostrou deficiente, pois diminui a capacidade de depuração uterina. LeBLANC et al. (1995) demonstrou que o principio ativo fenilbutazona para o tratamento de endometrite persistente pós-cobertura inibe a ação da enzima ciclooxigenase, bloqueando a síntese de prostaglandina e diminuindo assim a capacidade de limpeza do útero.

Em contra partida, o uso de antiinflamatórios esteroidais ou imunomoduladores, consegue reduzir a resposta imune ao diminuir a inflamação pós-cobertura FUMUSO et al., (2003), BUCCA et al., (2008), PAPA et al., (2008). O uso destas substâncias pode aumentar as taxa de prenhez em éguas com acumulo de fluído uterino. DELL'AQUA Jr. et al. (2006) obtiveram sucesso no uso de antiinflamatório esteroidal (acetato de prednisolona) em um grupo de éguas que apresentavam histórico de acúmulo de fluido uterino, (os animais receberam o tratamento a cada 12 horas, iniciando 2 dias antes da 
SILVA, F.M., BLUME, H. e OLIVEIRA, R.A. Endometrite persistente pós-cobertura. PUBVET, Londrina, V. 8, N. 20, Ed. 269, Art. 1796, Outubro, 2014.

inseminação e aplicação 1 dia após ovulação). Obtiveram uma melhora na taxa de prenhez e redução de fluido uterino, o que possivelmente se deva a modulação de várias citocinas, causadas pelos corticóides, pois reduz a inflamação (MALSCHITZKY et al., 2007).

A eficácia no tratamento deste tipo de endometrite foi demonstrada por FIORATTI (2010), que obteve $40 \%$ de aumento na taxa de recuperação embrionária com o uso de dexametasona. Resultados semelhantes aos de BUCCA et al., (2008), que usaram uma dose única de dexametasona (50 $\mathrm{mg} / \mathrm{IV}$ ) associado a terapias rotineiras realizadas após a cobertura (lavagem uterina, drogas ecbólicas, e em alguns casos, antibióticos intrauterinos), e obtiveram aumento das taxas de prenhez em éguas com histórico de acúmulo de fluido após ovulação e em éguas com incompetência cervical.

\section{Plasma rico em plaquetas}

O uso de plasma rico em plaquetas tem sido uma técnica muito promissora no tratamento de endometrite persistente pós-cobertura, pois permite fazer uma modulação da reação inflamatória e promove uma reparação da lesão no tecido uterino.

O plasma rico em plaquetas é uma terapia que vem ocupando espaço por ser de baixo custo e de fácil aquisição. Ele é rico em fatores de crescimento importantes na reparação tecidual, por suas propriedades quimiotáxicas, neovasculares e mitogênicas. O plasma rico em plaquetas é derivado do sangue total, contendo cinco vezes mais o número de plaquetas que os níveis fisiológicos (KEVY \& JACOBSON, 2004).

As plaquetas participam de uma interação com os neutrófilos nos vasos sanguíneos, que resultam na biossíntese da lipoxina A4, que são moléculas moduladoras do processo inflamatório. Elas exercem diretamente uma diminuição na quimioatração de neutrófilos para o local lesado e também promovem a apoptose deles. Além dessas funções ainda fazem quimiotaxia para monócitos que vão se transformar em macrófagos nos tecidos para a resolução da inflamação e auxiliar na cicatrização (BANNENBERG et al., 2005). 
SILVA, F.M., BLUME, H. e OLIVEIRA, R.A. Endometrite persistente pós-cobertura. PUBVET, Londrina, V. 8, N. 20, Ed. 269, Art. 1796, Outubro, 2014.

Com isso entende-se que as plaquetas podem estar relacionadas com a resolução da inflamação. EL-SHARKAWY et al., (2007), notaram que as plaquetas induzem um aumento na quantidade de lipoxinas A4 e RANTES (quimiocinas secretadas por macrófagos e células endoteliais), tem também a função de manter o gradiente de quimiotaxia para a migração dos leucócitos da circulação para os tecidos e os RANTES possui a particularidade de atuar sobre basófilos fazendo que eles não liberem histamina, inibindo o processo de inflamação.

As plaquetas também tem o poder de causar uma inibição transitória da inflamação e, em um momento futuro estimular uma resposta mais potente para a resolução da inflamação. Isso se deve ao fato de que as plaquetas conseguem atuar na liberação de interleucina 1 pelos macrófagos. Em um momento inicial ocorre a supressão na liberação da interleucina 1 de macrófagos ativados e a liberação da interleucina sete dias depois em maior quantidade, segundo WOODALL et al., (2008).

\section{Manejo das coberturas}

O ideal é que essas éguas sejam cobertas ou inseminadas apenas uma vez por ciclo. Para isso é necessário o acompanhamento do desenvolvimento folicular com a indução da ovulação no momento adequado para que essa égua seja coberta apenas uma vez por ciclo estral. Faz-se necessário também a correção de problemas como a má conformação perineal que pode ser corrigida nos casos menos graves com um escore corporal adequado e nos casos mais graves com uma vulvoplastia.

\section{Conclusão}

Deve-se dar a devida importância às endometrites já que são responsáveis por índices reprodutivos insatisfatórios. Felizmente ao longo dos anos, muito se descobriu sobre os mecanismos envolvidos no desenvolvimento das endometrites e a partir dessas descobertas pode-se definir um tratamento mais adequado e também um prognóstico reprodutivo do animal. 
SILVA, F.M., BLUME, H. e OLIVEIRA, R.A. Endometrite persistente pós-cobertura. PUBVET, Londrina, V. 8, N. 20, Ed. 269, Art. 1796, Outubro, 2014.

Há que se enfatizar a necessidade de monitorar as éguas consideradas susceptíveis antes e após as coberturas durante toda a estação reprodutiva, dando maior importância aos tratamentos que têm o intuito de auxiliar o útero a eliminar fisicamente o conteúdo uterino.

Entretanto, há ainda muito o que descobrir para que as endometrites não sejam mais responsáveis por índices reprodutivos aquém dos ideais na espécie equina.

\section{Referências}

1. ALGHAMDI, A.S.; FOSTER, G.N.; TROEDSSON, M.H.T. Nitric oxide levels and nitric oxide synthase expression in uterine samples from mares susceptible and resistant to persistent breeding-induced endometritis. American Journal of Reproductive Immunology, v.53, p.230-237, 2005.

2. BANNENBERG, G.L.; CHIANG, N.; ARIEL, A.; TJONAHEN, E., GOTLINGER, K.H., HONG, S., SERHAN, C.N. Molecular circuits of resolution: Formation and actions of resolvins and protectins. The Journal of Immunology, v.174, p.4345-4355, 2005.

3. BRINSKO, S.P.; RIGBY, S.L.; VARNER, D.D; BLANCHARD, J.L. A practical method for recognizing mares susceptible to post breeding endometritis. American Association of equine Practitioners, v.49, p.363-365, 2003.

4. BRINSKO, S.P.; VARNER, D.D.; SHUMACHER, J.; LOVE, C.C.; HINKICHS, K.; HARTMAN, D. Manual of Equine Reproduction. 3 ed. Elsevier, 2011. 190p.

5. BUCCA, S.; CARLI, A.; BUCKLEY, T.; DOLCI, G.; FOGARTY, U. The use of dexamethasone administered to mares at breeding time in the modulation of persistent mating induced endometritis. Theriogenology, v.70, p.1093-1100, 2008.

6. CADARIO, M.E.; THATCHER, W.W.; KLAPSTEIN, E.; MERRIT, A.M.; ARCHBALD, L.F.; THATCHER, M.J.; LeBLANC, M.M. Dynamics of prostaglandin secretion, intrauterine fluid and uterine clearance in reproductively normal mares and mares with delayed uterine clearance. Theriogenology, v.52, p.1181-1192, 1999.

7. CARD, C. Post-breeding inflammation and endometrial cytology in mares. Theriogenology, v.64, p.580-588, 2005.

8. COMBS, G.B.; LeBLANC, M.M; NEUWIRTH, L; TRAN, T.Q. Effects of Prostaglandin F2 alpha cloprostenol and fenprostalene on uterine clearance of radiocolloid in the mare. Theriogenology, v.45, p.1449-1455, 1996.

9. DeLL'AQUA Jr, J.A.; PAPA, F.O.; LOPES, M.D.; ALVARENGA, M.A.; MACEDO, L.P.; MELO, C.M. Modulation of acute uterine inflammatory response after insemination with equine frozen semen. Animal Reproduction Science, v.94, p.270-273, 2006.

10. EL-SHARKAWY, H.; KANTARCI, A.; DEADY, J.; HASTURK, H.; LIU, H.; ALSHAHAT, M.; VAN DYKE, T.E. Platelet-Rich Plasma: growth factors andanti-inflammatory properties. Journal of Periodontology. v.78, p.661-669, 2007. 
11. FIORATTI, E.G. Efeito dos anti-inflamátorios esteróides na reação inflamatória e na fertilidade de éguas normais e susceptíveis à endometrite persistente após inseminação artificial. 2010, 141p. Dissertação de Mestrado - Faculdade de Medicina Veterinária e Zootecnia Campus de Botucatu. Universidade Estadual Paulista "Júlio de Mesquita Filho", São Paulo, 2010.

12. FUMOSO, E.; AGUILAR, J.; GIGUERE, S.; DAVID, O.; WADE, J.; ROGAN, D. Interleukin-8 (IL-8) and 10 (IL-10) mRNA transcriptions in the endometrium of normal mares and mares susceptible to persistent post-breeding endometritis. Animal Reproduction Science, v.94, p.282-285, 2006.

13. GALINDO, A.S.D.; KUNZ, T.L.; GAMBARINI, M.L.; OLIVEIRA, B.D. Mecanismos de defesa uterinos na fêmea bovina. Revista do Conselho Federal de Medicina Veterinária, v.9, p.49-58, 2003.

14. HINRICHS, K.; CUMMINGS, M.R.; SERTICH, P.L.; KENNEY, R.M. Clinical significance of aerobic bacterial flora of the uterus, vagina, vestibule, and clitorial fossa of clinically normal mares. Journal of the American Veterinary Medical Association, v.193, p.72-75, 1988.

15. HEMBERG, E.; LUNDEHEIM, N.; EINARSSON, S. Retrospective study on vulvar conformation in relation to endometrial cytology and fertility in thoroughbred mares. Jounal Veterinary Medicine, v.38, p.198-210, 2005.

16. KATILA, T. Uterine defence mechanisms in the mare. Animal Reproduction Science, v.42, p.197-204, 1996.

17. KEVY, S.V.; JACOBSON, M.S. Comparision of methods for point of care preparation of autologous platelet gel. The Journal of Extra Corporeal Technology, v.36, p.28-35, 2004.

18. KNUTTI, B.; PYCOCK, J.F.; VAN DER WEIJDEN, G.C.; KUPPER, U. The influence of early post breeding uterine lavage on pregnancy rate in mares with intrauterine fluid accumulations after breeding. Equine Veterinary Education, v.5, p.346- 349, 2000.

19. LeBLANC, M.M.; JOHNSON, R.D.; CALDERWOOD MAYS, M.B.; VALDERRAMA, C. Lymphatic clearence of índia ink in reproductively normal mares and mares susceptibles to endometritis. Biology Reproduction Mono, v.1, p.501-506, 1995.

20. LeBLANC, M.M Advances in the diagnosis and treatment of chronic infectious and postmating-induced endometritis in the mare. Reproduction Domestic Animal, v.45, p.21-27, 2010.

21. LeBLANC, M.M. Persistent mating-induced endometritis. In: ROBINSON, N.E. Current therapy in equine medicine, 5.ed. St. Louis: Elsevier Science, 2003. p.234-237.

22. LeBLANC, M.M.; CAUSEY, R.C. Clinical and Subclinical Endometritis in the Mare: Both threats to Fertility. Reproduction of Domestic Animals, v.44, p.10-22, 2009.

23. LeBLANC, M.M.; NEUWIRTH, L.; MAURAGIS, D.; KLAPSTEIN, E.; TRAN, T. Oxytocin enhances clearance of radiocolloid from the uterine lumen of reproductively normal mares and mares susceptible to endometritis. Equine Veterinary Journal, v.26, p.279-282, 1994.

24. LEWIS, G.S. Steroidal regulation of uterine immune defenses. Animal Reproduction Science, v.2, p.281-294, 2004. 
25. LIEPINA, E., ALAMO, M.M.R., REILAS, T., KATILA, T. IL-6 and TNF-a expression in uterine fluids of mares with induced delay in uterine clearance. Animal Reproduction Science.v.7, p107-108, 2010.

26. MACKAY, R.J. Inflammation in horses. Veterinary Clinics of North America:Equine Practice, v.16, p. 15-27, 2000.

27. MALSCHITZKY, E.; JOBIM, M.I.M.; GREGORY, R.M.; MATTOS, R.C. Endometritis in the mare, new concepts. Revista Brasileira de Reprodução Animal, v.31, p.17-26, 2007.

28. MCRAE, A.C. The blood uterine lumen barrier and exchange betweenextracellular fluids. Journal of Reproduction and Fertility, v.82, p.857-873, 1988.

29. NIKOLAKOPOULOS, E.; WATSON, E.D. Uterine contractility is necessary for the clearance of intrauterine fluid but not bacteria after bacterial infusion in the mare. Theriogenology, v.52, p.413-423, 1999.

30. PAPA, F.O.; DELL'AQUA J.A Jr; ALVARENGA, M.A.; MELO, C.M.; SOARESZ.F.; LOPES, M.D. Use of corticosteroid therapy on the modulation of uterine inflammatory response in mares after artificial insemination with frozen semen. Pferdeheilkunde, v.24, p.79-82, 2008.

31. PRESCOTT, L.M., HARLEY, J.P., KLEIN, D.A. (Eds). (2005). Microbiology. 6th ed., New York USA. McGraw-Hill. McGraw-Hill Companies Inc.

32. REITZENSTEIN, M.; CALLHAN, M.A.; HANSEN, P.J.; LeBLANC, M.M. Aberrations in uterine contractile patterns in mares with delayed uterine clearance after administration of detomidine and oxytocin. Theriogenology, v.58, p.887-898, 2002.

33. RIGBY, S.L.; HILL, J.; MILLER, C.; THOMPSON, J.; VARNER, D.D.; BLANCHARD, T. Administration of oxytocin immediately after insemination does not improve pregnancy rates in mares bred by fertile or subfertile stallions. Theriogenology, v.51, p.1143-1150, 1999.

34. SCHUBERTH, H.J., TAYLOR, U., ZERBE, H., WABERSKI, D., HUNTER, R., RATH, D. Immunological responses to semen in the female genital tract. Theriogenology, v.70, p.1174- 1181, 2008.

35. TIZARDI, I.R. Resistência às bactérias. Imunologia veterinária. 5ed. São Paulo: Editora Roca, 1998. p.294-309.

36. TROEDSSON, M.H.T Therapeutic considerations for mating-induced endometritis. Pferdeheilkunde, v.13, p.516- 520, 1997.

37. TROEDSSON, M.H.T. Uterine clearance and resistance to persistentendometritis in the mare. Theriogenology, v.52, p.461-471,1999.

38. TROEDSSON, M.H.T. Breeding-induced endometritis in mares.Veterinary Clinics of North America: Equine Practice, v.22, p.705-712, 2006.

39. VANDERWALL, D.K.; WOODS, G.L. Effect on fertility of uterine lavage performed immediately prior to insemination in mares. Journal of American Veterinary Medicine Association, v.222, p.1108-1119, 2003.

40. VERONESI, M.C.; CARLLUCIO, A.; KINDHAL, H.; FAUSTINI, M.; BATTOCCHIO, M. CAIROLI, F. Oxytocin- induced PGF2a release in mares with and without post-breeding delayed uterine clearance. Journal of Veterinary Medicine, v.53, p.259-262, 2006. 
41. VON REITZENSTEIN M.; CALLAHAN, M.A.; HANSEN, P.J.; LeBLANC, M.M. Aberrations in uterine contractile patterns in mares with delayed uterine clearance after administration of detomidine and oxytocin. Theriogelonogy, v.58, p. 887- 898, 2002.

42. WOODALL, J. Jr.; TUCCI, M.; MISHRA, A.; ASFOUR, A.; BENGHUZZI, H. Cellular effects of platelet rich plasma interleukin1 release from PRP treated macrophages. Biomedical Sciences Instrumentation, v.44, p.489-494, 2008.

43. ZENT, W.W.; TROEDSSON, M.H.T.; XUE, J.L. Post-breeding uterine fluid accumulation in a normal population of thoroughbred mares: a field study. Proceedings of American Association of Equine Practitioners. 1998, v.44, p.64-65. 